\title{
Chronic Ampakine Treatments Stimulate Dendritic Growth and Promote Learning in Middle-Aged Rats
}

\author{
Julie C. Lauterborn, ${ }^{1 \star}{ }^{1}$ Linda C. Palmer, ${ }^{1 \star}$ Yousheng Jia, ${ }^{1}$ Danielle T. Pham, ${ }^{1}$ Bowen Hou, ${ }^{1}$ Weisheng Wang, ${ }^{1}$ \\ Brian H. Trieu, ${ }^{1}$ Conor D. Cox, ${ }^{1}{ }^{\circledR}$ Svetlana Kantorovich, ${ }^{1}$ Christine M. Gall, ${ }^{1,2 *}$ and Gary Lynch ${ }^{1,3 *}$ \\ ${ }^{1}$ Department of Anatomy and Neurobiology, ${ }^{2}$ Department of Neurobiology and Behavior, and ${ }^{3}$ Department of Psychiatry and Human Behavior, University \\ of California, Irvine, California 92697
}

Positive allosteric modulators of AMPA-type glutamate receptors (ampakines) have been shown to rescue synaptic plasticity and reduce neuropathology in rodent models of cognitive disorders. Here we tested whether chronic ampakine treatment offsets age-related dendritic retraction in middle-aged (MA) rats. Starting at 10 months of age, rats were housed in an enriched environment and given daily treatment with a short half-life ampakine or vehicle for 3 months. Dendritic branching and spine measures were collected from 3D reconstructions of Lucifer yellow-filled CA1 pyramidal cells. There was a substantial loss of secondary branches, relative to enriched 2.5-month-old rats, in apical and basal dendritic fields of vehicle-treated, but not ampakine-treated, 13-month-old rats. Baseline synaptic responses in CA1 were only subtly different between the two MA groups, but long-term potentiation was greater in ampakine-treated rats. Unsupervised learning of a complex environment was used to assess treatment effects on behavior. Vehicle- and drug-treated rats behaved similarly during a first $30 \mathrm{~min}$ session in the novel environment but differed markedly on subsequent measures of long-term memory. Markov sequence analysis uncovered a clear increase in the predictability of serial movements between behavioral sessions 2 and 3 in the ampakine, but not vehicle, group. These results show that a surprising degree of dendritic retraction occurs by middle age and that this can be mostly offset by pharmacological treatments without evidence for unwanted side effects. The functional consequences of rescue were prominent with regard to memory but also extended to self-organization of behavior.

Key words: CA1; enriched environment; hippocampus; long-term potentiation; Markov analysis; spine

Significance Statement

Brain aging is characterized by a progressive loss of dendritic arbors and the emergence of impairments to learning-related synaptic plasticity. The present studies show that dendritic losses are evident by middle age despite housing in an enriched environment and can be mostly reversed by long-term, oral administration of a positive allosteric modulator of AMPA-type glutamate receptors. Dendritic recovery was accompanied by improvements to both synaptic plasticity and the encoding of long-term memory of a novel, complex environment. Because the short half-life compound had no evident negative effects, the results suggest a plausible strategy for treating age-related neuronal deterioration.

\section{Introduction}

AMPA-type glutamate receptors are tetrameric complexes that organize into two transmembrane dimers. Ampakines (AKs) are

Received Aug. 21, 2015; revised Dec. 21, 2015; accepted Dec. 23, 2015.

Author contributions: J.C.L., L.C.P., Y.J., D.T.P., B.H., W.W., B.H.T., C.D.C., C.M.G., and G.L. designed research; J.C.L., L.C.P., Y.J., D.T.P., B.H., W.W., B.H.T., C.D.C., S.K., and G.L. performed research; J.C.L., L.C.P., Y.J., D.T.P., B.H., W.W., B.H.T., C.D.C., S.K., C.M.G., and G.L. analyzed data; J.C.L., L.C.P., D.T.P., C.D.C., C.M.G., and G.L. wrote the paper.

This research was supported in part by National Institute of Neurological Disorders and Stroke Grants NS045260 and NS085709, Office of Naval Research Multidiciplinary University Research Initiative Grant N00014-10-1-007, National Science Foundation Grant 1146708 and Fellowship DGE0808392 (C.D.C), National Institutes of Health Grant T32 NS45540 (S.K.), and the University of California Irvine Center for Autism Research and Treatment. J.C.L., C.M.G., and G.L. are coauthors on patents, held by the University of California, for the use of ampakines to offset neurodegenerative changes and to facilitate learning. small molecules that bind to a site at the dimer interfaces (Jin et al., 2005) and thereby slow two basic properties of ligand-bound receptors: (1) deactivation resulting from dissociation of transmitter; and (2) desensitization attendant to relaxation of the dimerized state (Arai et al., 2000). Together, these two effects prolong the open time of the AMPA receptor ion channel and increase the amplitude and duration of fast, excitatory transmis-

G.L. and C.M.G. own stock ( < 5\%) in a publicly traded company investigating positive AMPA receptor modulators for an indication unrelated to the present study but do not receive funding from or interact with that entity.

*J.C.L., L.C.P., C.M.G., and G.L. contributed equally to this work.

Correspondence should be addressed to either Drs. Gary Lynch or Christine Gall, Department of Anatomy and Neurobiology, University of California, Irvine, CA 92697-1275, E-mail: ga.s.lynch@gmail.com or cmariegall@gmail.com.

DOI:10.1523/JNEUROSCI.3157-15.2016

Copyright $\odot 2016$ the authors $\quad 0270-6474 / 16 / 361636-11 \$ 15.00 / 0$ 
A

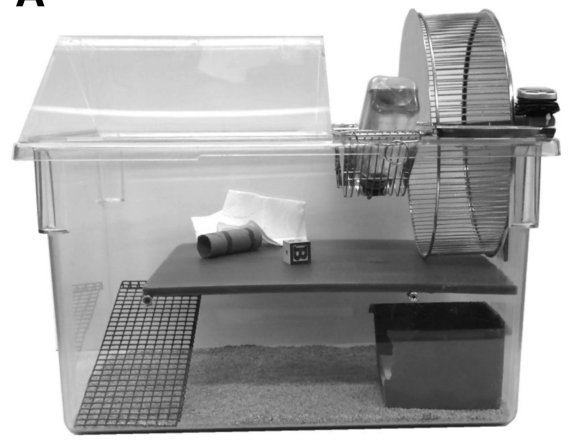

C

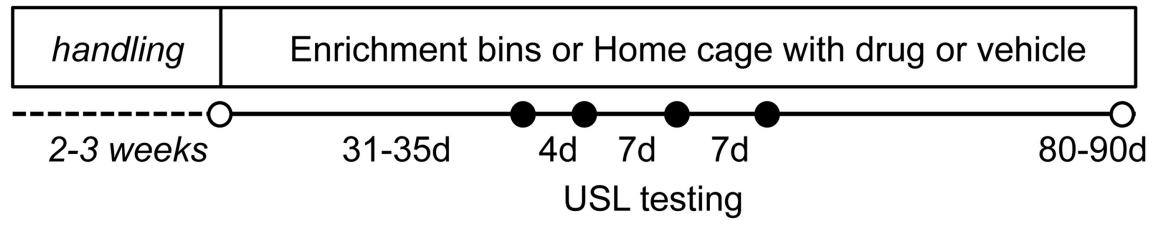

Figure 1. EE, behavioral testing, and drug treatments. $A$, Photograph of EE housing bin with nest box on the lower level, ladder to second level with enrichment objects (cardboard tube), running wheel, and novel object (wooden block). B, Overhead infrared camera view of a rat in the USL apparatus showing the dark refuge at the left; passages through walls separating the four arena quadrants are indicated by arrows. Four distinct objects ( 2 with moving parts, 2 without) were located centrally in each arena room. C, Experimental schedule: rats were handled and trained to drink Veh from a syringe for 2 to 3 weeks and then housed in EE bins or home cages and given daily AK or Veh orally for the duration of the study. Thirty minute USL sessions began during week 5 of enrichment and drug/Veh treatment; session 2 was given $4 \mathrm{~d}$ after the first and subsequent sessions given at $7 \mathrm{~d}$ intervals. After final testing, rats continued treatment until they were killed for dendritic analysis at day 80 or electrophysiology at day $81-90$ (in pairs).

sion (Arai et al., 2002; Lynch, 2006). Besides increasing communication within networks, AK-induced enhancement of EPSCs lowers the threshold for long-term potentiation (LTP; Stäubli et al., 1994) and upregulates production of brain-derived neurotrophic factor (BDNF; Lauterborn et al., 2000; Simmons et al., 2011). The first of these effects is related to the depolarization needed to unblock NMDA receptors that trigger LTP, whereas the second reflects the dependency of BDNF gene expression on excitatory drive.

The above results prompted studies testing whether semichronic AK treatments could offset the defects in synaptic plasticity found in rodent models of human conditions associated with memory and/or cognitive problems. Positive results were obtained for five different models (Rex et al., 2006; Simmons et al., 2009, 2011; Baudry et al., 2012; Kramár et al., 2012a). Moreover, and as predicted from neuroprotective properties of BDNF, several weeks of AK treatment markedly reduced degeneration in the striatum of mice overexpressing the huntingtin gene mutation associated with Huntington's disease (Simmons et al., 2011).

The present studies addressed the question of whether AK treatment could offset the age-related retraction of dendritic branches previously described in the cortex, hippocampus, and other areas in rodents and primates (Dickstein et al., 2013; Samson and Barnes, 2013) and what are likely associated age-related changes in LTP and learning (Landfield and Lynch, 1977; Burke and Barnes, 2006; Wilson et al., 2006; Robitsek et al., 2008; Kumar, 2011). We assessed drug actions in healthy 13-month-old middle-aged (MA) rats that were housed in a complex enriched environment (EE) to avoid possible effects of living in the impoverished circumstances associated with standard rodent housing. Comparisons with measures from EE-housed, 2.5-month-old rats were used to gauge the extent to which AK treatment in older animals returns dendritic branching to what might be considered a baseline condition. Finally, electrophysiological and behavioral tests of vehicle (Veh)- and AKtreated MA rats provided tests for functional consequences predicted from changes in dendritic morphology and assays for side effects arising from long-term drug treatment.

\section{Materials and Methods}

Animals, EE, and drug treatments. All procedures were conducted in accordance with the U.S. Public Health Service Policy on Humane Care and Use of Laboratory Animals and protocols approved by the Institutional Animal Care and Use Committee of University of California Irvine. Ten-month-old male Long-Evans rats (Harlan Labs) were maintained in single housing to avoid fighting; after initial handling (2-3 weeks), rats were assigned randomly to Ampakine + Enrichment or Vehicle + Enrichment groups for morphology studies. Enrichment entailed housing in EE bins (Fig. 1) for $80-81 \mathrm{~d}$. For electrophysiology studies, 10 -month-old rats were assigned randomly to Ampakine + Enrichment or Vehicle + Enrichment groups and housed in the EE bins with daily AK or Veh treatment for $80-89 \mathrm{~d}(n=6$ per group). Thus, at time of analyses, the MA rats were $\sim 13$ months of age. For morphology studies only, 5- to 6-week-old $(n=7)$ rats were handled twice daily for $4 \mathrm{~d}$ and then housed in groups of four in the same EE bins used for older animals. These young rats were 2.5 months old at the time they were killed; longer periods of enrichment were not used for this group because of published evidence that aging-related changes are already evident in rat brain by 6 months (Navarro-Mora et al., 2011; Nell et al., 2015). All housing was under a reverse $12 \mathrm{~h}$ light/dark cycle.

EE housing for both MA and young rats consisted of a multi-tiered bin (Fig. $1 A$ ) with full access to a 15 -inch running wheel, nest box, bedding, chewable enrichment items, food and water ad libitum, and novel items that were switched weekly. MA rats received the AK CX929 $(5 \mathrm{mg} / \mathrm{kg}$ in $10 \%$ honey in water) or Veh ( $10 \%$ honey water) orally on a $5 \mathrm{~d}$ on $/ 2 \mathrm{~d}$ off schedule throughout. Treatments were presented in a $1 \mathrm{cc}$ syringe and were readily consumed throughout the study. CX929 has a short $(<15$ $\mathrm{min}$ ) half-life in the blood (Rex et al., 2006). Behavioral and electrophysiological measures were conducted 20-24 h after the most recent dose, thus without circulating drug present. We confirmed that oral administration of CX929 produces the widely reported pattern of behavioral changes found with high levels of AKs: agitation and then prodromal effects as dosage is increased. These effects are evident within 10-20 min of receiving doses of 20 and $40 \mathrm{mg} / \mathrm{kg}$; rats appeared normal after $50 \mathrm{~min}$. All of the studies reported here used $5 \mathrm{mg} / \mathrm{kg}$, as in previous work (Rex et al., 2006; Simmons et al., 2011; Baudry et al., 2012; Kramár et al., 2012a).

Unsupervised learning. Behavioral measures were collected from MA rats during the period of EE housing. Starting in week 5 of EE housing, MA rats were given $30 \mathrm{~min}$ sessions of free exploration in a novel, complex environment, with intertrial delays of 4 days (session 1 to session 2) or 7 days (subsequent sessions; Fig. $1 B, C$ ). The unsupervised learning (USL) environment consisted of a $1 \mathrm{~m}$ square arena with 18 -inch-high acrylic walls, open at the top, with an attached $18 \times 6 \times 5$ inch "refuge" constructed of black, infrared-transparent acrylic accessible via a 4-inch square opening. The large arena space was divided into four "rooms" with passages between them. Each room contained an object (chromed steel, ceramic, or acrylic mounted on a weighted powder-coated steel base). Movements were captured via an overhead infrared camera; ANYmaze (Stoelting) and in-house software was used to quantify behaviors, 
and a Markov sequence analysis (MATLAB; MathWorks) was used to evaluate errors in predictions of patterned movements. Statistical tests used R, Prism (GraphPad Software), and Excel (Microsoft). Because the drug suspension is visually distinct from the Veh, its administration was not blinded. On test days, drug or Veh was administered after testing was completed. Personnel placing the rats into the testing apparatus were the same as those administering the daily treatments with Veh or AK because older male rats can be aggressive with unfamiliar persons. However, all behavioral data were collected automatically from videos using ANYmaze software (Stoelting), and final statistical analyses were done by different investigators. Behavioral measures included distance traveled, speed of movement, number of forays, and time spent near or away from walls. Statistical differences between groups were determined using repeated-measures (RM) ANOVA and two-tailed Student's $t$ tests (Prism). The dip test for unimodality was used to test for subgroups among the Veh- and AK-treated rats (Hartigan and Hartigan, 1985).

Markov sequence analyses for behavior. To analyze the sequences of decisions made by rats when exploring an environment, a Markov chain analysis was performed (van der Heijden et al., 1990). The goal was to determine (1) how well the short-term decisions rats make during exploration predict longer sequences and (2) at what scale information was being added. Using ANY-maze software, video recordings were processed to obtain trajectories of each rat's position at $\sim 0.1 \mathrm{~s}$ intervals. For this analysis, the arena was divided into 10 locations; custom scripts in MATLAB version 7.8 were used to chunk each rat's trajectory while in the arena into $2.5 \mathrm{~s}$ intervals, and the rat's position at the start and end of each time segment was determined. This information was used to create a matrix of transition probabilities between the 10 possible arena locations, and then a set of "ideal prediction matrices" was constructed for successive $n$ and the original $2.5 \mathrm{~s}$ matrix was raised to the $n$th power; here $n$ represents the number of positions predicted forward (e.g., $n=2$ indicates the prediction of the rat's location using $5 \mathrm{~s}$ bins; $n=3$ indicates the prediction on 7.5 s, etc.; Walsh and Cummins, 1976). Data were then split into the different bin sizes, and the corresponding empirical transition matrices were calculated per animal. The predicted position was subtracted from the actual position and squared to yield the error; this error was multiplied by the time at each location to correct for the influence of rare events. On any session day, if a rat's prediction error was $>4$ SDs from the group mean for $>50 \%$ of the prediction steps, then the animal was dropped from analysis; this exclusion factor resulted in one to two animals per group being excluded per session. The final Markov sequence analysis included nine MA-AK rats and $11 \mathrm{MA}-\mathrm{Veh}$ rats (for all three sessions).

The equation 'Prediction Error $=\Sigma\left(T_{1}^{n}-T_{n}\right)^{2} \times$ Proportion' shows the prediction error calculation where $n$ is the number of steps forward predicted, $T_{1}$ is the original prediction matrix, which is raised to the $n$th power (yielding the $n$th ideal prediction matrix), $T_{n}$ is the empirical prediction matrix for that $n$, and Proportion is the relative time spent at a given location.

Electrophysiology. Acute hippocampal slices were prepared (400 $\mu \mathrm{m}$ thick) and maintained in an interface recording chamber with constant ACSF perfusion $\left(31^{\circ} \mathrm{C}\right)$ and allowed to stabilize in the recording chamber for $1.5 \mathrm{~h}$ before use (Trieu et al., 2015). Schaffer-commissural (S-C) fEPSPs, input/output curves, and paired-pulse facilitation were recorded in CA1b stratum radiatum as detailed previously (Rex et al., 2006; Trieu et al., 2015). For induction of LTP, two trains of theta burst stimulation (TBS; 10 bursts at $100 \mathrm{~Hz}, 200 \mathrm{~ms}$ between bursts) were applied, with a spacing of $50 \mathrm{~s}$, to the S-C projections (Kramár et al., 2012b). The magnitude of potentiation was evaluated 50-60 min after TBS and expressed as the percentage increase in fEPSP slope relative to baseline (pre-TBS) responses. Data were collected from three to five slices per rat using multiple physiology rigs and from at least five rats per group for each endpoint measure; all illustrations show mean \pm SEM values, with $n$ values representing slices per group. An initial group of slices was run unblinded to test for any obvious differences in synaptic responses between the MA-Veh versus MA-AK groups ( $n=1$ rat per group). Such effects were not found. The remaining majority of cases were run blind to treatment. Standardized procedures comparable with those described in previous work (Rex et al., 2006; Kramár et al., 2012b; Trieu et al., 2015) were followed. However, with prioritization of tissue handling for electrophysiology, it was not possible to collect hippocampal tissue of sufficient quality and quantity to perform low-variability biochemical assays (e.g., BDNF levels).

Cell fills and analyses. Rats were intracardially perfused with $4 \%$ paraformaldehyde/0.1 M phosphate buffer (PB), $\mathrm{pH}$ 7.4; brains were immediately removed from the skull, postfixed in the perfusate for $24 \mathrm{~h}$, and then sectioned through the hippocampus at $250 \mu \mathrm{m}$ on the coronal plane using a Leica vibroslicer 1000S (Miguéns et al., 2015). Pyramidal cells in subfield CA1b (four to five per slice through the mid-septotemporal hippocampus) were selected for filling under visual control and were impaled with a sharp micropipette (100 M $\Omega$ ) loaded with 5\% Lucifer yellow (Invitrogen) in $\mathrm{H}_{2} \mathrm{O}$; a direct negative current of 3-8 $\mathrm{nA}$ was applied until the dye filled distal processes and no additional loading was observed ( $\sim 15-20 \mathrm{~min})$. Sections were fixed again in $4 \%$ paraformaldehyde plus $0.125 \%$ glutaraldehyde in PB for $24 \mathrm{~h}$, washed in PB, slide mounted, and coverslipped with Vectashield (Vector Laboratories). Cell fills and all subsequent analyses of dendrites and spines were conducted blind to group.

Images of apical and basal dendritic trees were captured using a twophoton microscope built on an Olympus frame (ThorLabs) with MaiTai laser (Spectra-Physics) and 1.4 numerical aperture (NA), $63 \times$ objective. $z$ stacks of each dendritic span were collected using $1 \mu \mathrm{m}$ steps. For spine analyses, $z$ stacks were collected at Nyquist rate (1.4 NA, 63 $\times$ objective) with $0.13 \mu \mathrm{m}$ steps from first-order basal and second-order apical dendrites. All $z$ stacks included on average the first $30-50 \mu \mathrm{m}$ of the dendrite from the point of emergence. Stacks were deconvolved using AutoQuant version 2.2.1 (Media Cybernetics), and 3D builds were made using Imaris software version 7.6.1 and the Filament Tracer module (Bitplane).

Dendritic branching and lengths were measured using Imaris automated Sholl analysis, with $15 \mu \mathrm{m}$ ring spacing, and dendrite branch level analyses, respectively (Lauterborn et al., 2015). Significance was determined by two-way ANOVA (treatment vs dendritic distance; GraphPad Prism version 5.0a), followed by Tukey's HSD post hoc analyses (SPSS version 20; IBM). One-way ANOVA was performed using GraphPad Prism version 5.0a, followed by either Student-Newman-Keuls (SNK) multiple comparison or Tukey's tests. Cells with overlapping dendritic branches were not analyzed. The length of time needed to generate the number of cells required for each animal and the use of three groups, while maintaining tissue and labeling quality throughout, precluded testing for areas outside of field CAlb.

Spine measures. 3D renderings were prepared (Lauterborn et al., 2015) for 51 apical and 77 basal dendrites from MA-Veh rats, 32 apical and 72 basal dendrites from MA-AK rats, and 41 apical and 57 basal dendrites from young (2.5 months old) rats. The Imaris automatic seed point detector function was used to identify spine heads and necks (Lauterborn et al., 2015). Spine length was defined as the sum of the radius of the spine terminal point and spine neck length, extending from the head to the point of attachment on the dendrite. Maximum spine length and minimum spine end diameter were 5 and $0.2 \mu \mathrm{m}$, respectively; objects not fitting these size constraints were excluded from analysis. These parameters for the automated analyses have been shown to produce high accuracy in spine measures relative to estimated population statistics based on ultrastructural data (Swanger et al., 2011). Features of spines measured included the following: (1) neck length; (2) minimum neck diameter (Dn); (3) head diameter (Dh); and (4) overall spine length (neck plus head). Measures from 3D renderings were exported to Excel (Microsoft). Total numbers of spines analyzed in each field were 1730 (apical) and 2907 (basal) for MA-Veh, 2213 (apical) and 3458 (basal) for MA-AK, and 2635 (apical) and 2041 (basal) for young groups. Spine classifications were as follows: (1) without necks were termed "no necks"; (2) overall length $<0.5 \mu \mathrm{m}$ and $\mathrm{Dn} / \mathrm{Dh}>0.5$ was considered "stubby"; (3) Dn/ $\mathrm{Dh} \leq 0.5$ was considered "mushroom"; and (4) both total length $>0.5$ $\mu \mathrm{m}$ and $\mathrm{Dn} / \mathrm{Dh} \geq 0.5$ identified a spine as "long-thin." Spines outside of these criteria were classified as "other" (modified from Harris et al., 1992). Statistical differences between the three groups were determined using one-way ANOVA or RM-ANOVA, followed by SNK test (Prism). 

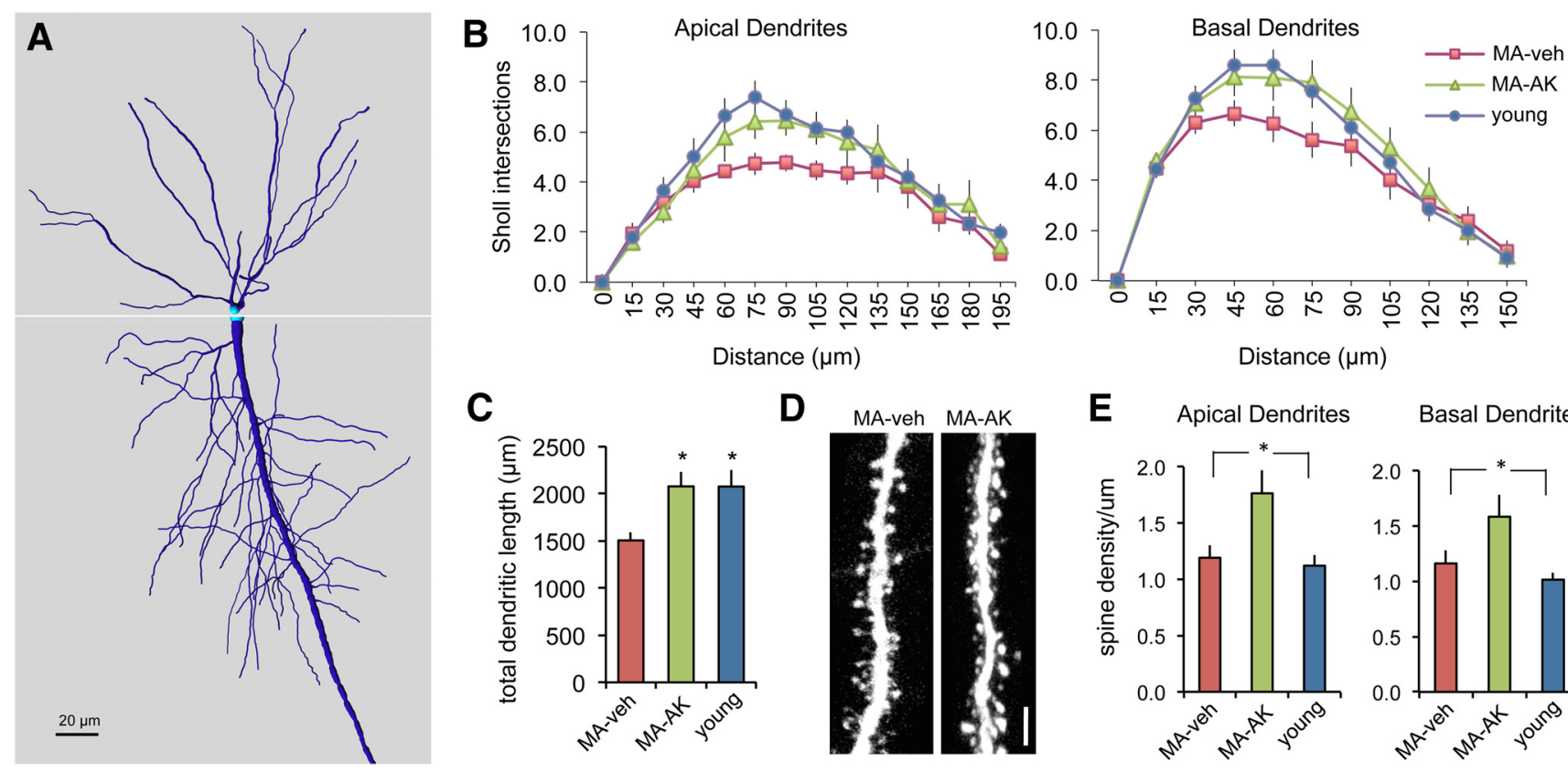

Basal Dendrites

Figure 2. AK treatments increased dendritic branching and spine density in MA rats. A, Imaris-generated build of the apical (bottom) and basal (top) dendrites of a CA1 pyramidal neuron from a 2.5-month-old rat. $\boldsymbol{B}$, Sholl analyses show the number of intersections for apical and basal dendrites through the depth of each field: in both, MA-Veh rats had fewer intersections, and thus branches, than MA-AK rats. For basal dendrites, $p=0.047$ for group effect, $p<0.001$ for distance effect, two-way ANOVA; $p=0.04$ for MA-AK versus MA-Veh; $p=0.622$ for MA-AK versus young, 2.5 month olds; $p=0.20$ for MA-Veh versus young, Tukey's test (apical field statistics in Results). C, Aggregate dendritic length (apical plus basal) for all groups ( ${ }^{*} p<0.05$ young vs MA-Veh, SNK test; MA-AK vs young, NS). D, Images of Lucifer yellow-filled spiny apical dendrites from MA-Veh and MA-AK rats. Scale bar, $2 \mu \mathrm{m}$. $\boldsymbol{E}$, Graphs show spine density on apical secondary and basal dendrites (apical, $p=0.009$, 1-way ANOVA; basal, $p=0.017$, 1-way ANOVA; ${ }^{p} p<0.05$, SNK test). Mean \pm SEM values are shown; $n=6$ for MA-Veh, 5 for MA-AK, and 7 for young group.

\section{Results}

MA male Long-Evans rats were maintained in EE housing beginning at 10 months of age; subgroups received the AK CX929 or Veh, orally with a schedule of $5 \mathrm{~d}$ on/2 $\mathrm{d}$ off for a period of 3 months. All rats were tested periodically for patterns of exploration in a complex environment that was different from their $\mathrm{EE}$ housing (Fig. 1). Separate cohorts of Veh- and AK-treated MA rats were evaluated for effects on dendritic morphology and synaptic plasticity in the hippocampal field CA1 promptly at the end of treatment (i.e., at 13 months of age).

\section{AK treatment increased dendritic branching}

In fixed tissue sections, field CA1 stratum pyramidale neurons were filled with Lucifer yellow as described previously (Miguéns et al., 2015). An average of six filled neurons were reconstructed (Fig. 2A) per rat, and, from these $3 \mathrm{D}$ reconstructions, measures of dendritic branching and spine elaboration were collected. A group of 2.5-month-old young rats that had lived in an EE for 1 month was included here to provide a baseline against which to test whether the dendritic retraction reported previously for older animals occurs by middle age and despite environmental enrichment.

Sholl analyses of apical dendritic branching (Lauterborn et al., 2015) in Veh-treated MA rats corroborate reports that aging results in substantial dendritic retraction (Dickstein et al., 2007) but further show that these effects are significant by middle age despite EE housing (Fig. 2B, left). In marked contrast, Sholl curves for AK-treated MA rats were not different from those of young rats ( $p<0.0001$, RM-ANOVA for the 3 groups; young vs MA-Veh, $p<0.0001$; young vs MA-AK, $p>0.50$; MA-Veh vs MA-AK, $p<0.008$; Tukey's tests). Treatments had similar effects on the basal dendrites: there were fewer dendritic branches in MA-Veh rats relative to 2.5 -month-old $(p<0.003)$ or MA-AK $(p=0.001)$ rats and no difference between the latter groups $(p>$ 0.35 ; Fig. $2 B$, right). Total dendritic length also was reduced with aging, and this effect was eliminated by AK treatment ( $p=0.016$ for three groups, one-way ANOVA; $p<0.05$ for young vs MAVeh; $p<0.05$ for MA-Veh vs MA-AK; NS for young vs MA-AK; SNK test; Fig. 2C). Collectively, these findings constitute evidence that long-term AK treatment reduces age-related losses in dendritic branches; it should be noted that the length measurements may underestimate the differences between the groups because of branches coursing out of the plane of the thick sections.

Next, we assessed AK treatment effects on dendritic spines. There was no age-related change in the number of spines per micrometer ( $p>0.5$, SNK test for MA-Veh vs young), a result that accords with previous reports for field CA1 (Markham et al., 2005). However, spine density was increased above MA-Veh and young 2.5-month-old values in both apical and basal dendritic fields of AK-treated MA rats ( $p<0.05$ all cases, SNK test; Fig. $2 D, E)$. These results suggest that AK treatment stimulates both spine and dendritic growth: for dendritic arbors, this offsets reductions in branching that are otherwise evident with age, whereas for spine densities AK treatment increased counts to supranormal levels.

Past studies have described changes in spine morphology in the aged brain (Petralia et al., 2014), although data are lacking for MA animals and enrichment protocols as used here. Qualitative examination did not reveal any striking differences in staining intensity or general appearance of spines between the three groups (Fig. $3 A$ ). Spine necks present a barrier to the diffusion of molecules into the spine head (Nimchinsky et al., 2002); that the dye reached isolated compartments to approximately the same degree in the three groups constitutes evidence that its diffusion did not differ greatly between them. This accords with previous 
A

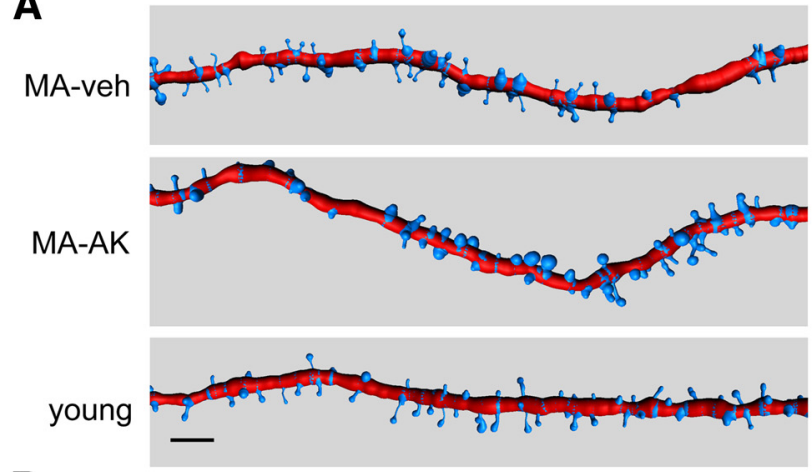

B

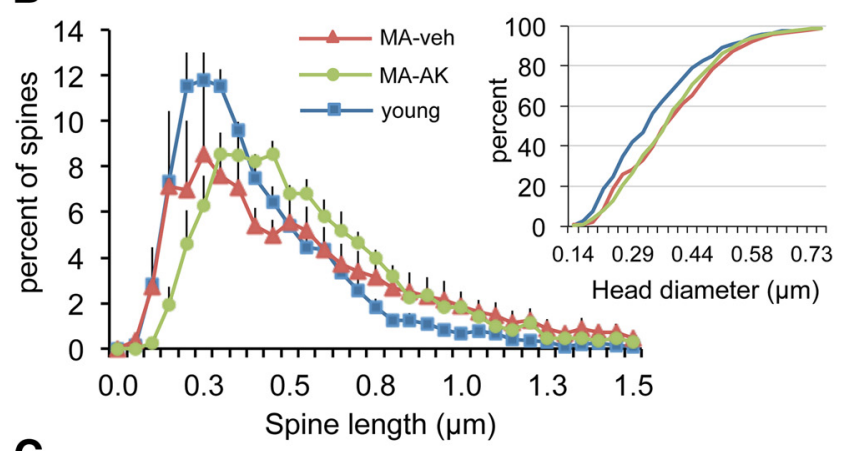

C

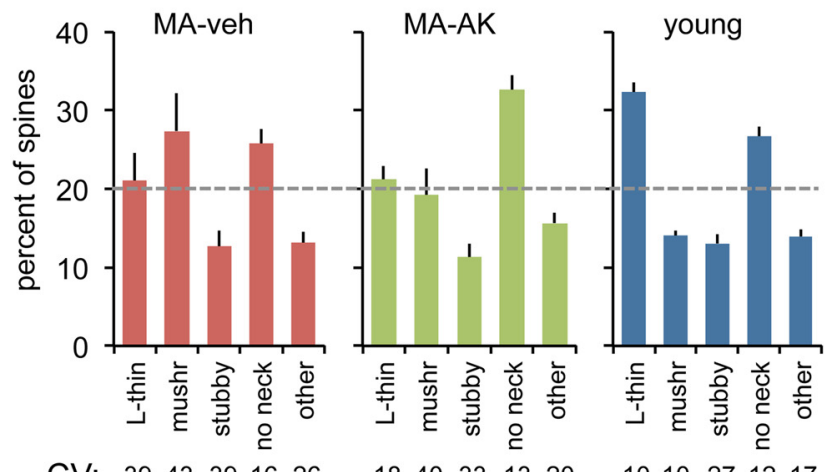

CV: $3943 \quad 391626$

$1840 \quad 3313 \quad 20$

$1010 \quad 271217$

Figure 3. AK treatment had modest effects on spine shape. Spans of basal and secondary apical dendrites were 3D reconstructed, and spine measures were collected using Imaris. $\boldsymbol{A}$, Automated 3D reconstructions of secondary apical dendrites from the different treatment groups with dendritic shafts indicated in red and spines in blue. $\boldsymbol{B}$, Graphs show the proportion of spines with various lengths (left) and the cumulative frequency distributions for spine head diameter (right) for MA-Veh $(n=6)$, MA-AK ( $n=5)$, and young, 2.5-month-old (Veh-treated; $n=7$ ) groups: MA groups had similar curves that contrasted with the young group. C, Graphs show the percentage of spines classified as long-thin (L-thin), mushroom (mushr), stubby, no neck, or other. The MA-AK group had greater numbers of spines with no neck; the young group had proportionately more long-thin spines than either MA group. For statistics, see Results; means \pm SEMs are shown. The CV for spines within of each shape category is given at the bottom; the mean CV values for each treatment group are presented in Results.

results using the dye-fill technique in fixed tissue from aged brains (Ohm and Diekmann, 1994; Hao et al., 2006; Pereira et al., 2014). Next, we used Imaris software to reconstruct in 3D spans of Lucifer yellow-labeled basal and secondary apical dendrites to provide quantitative measures of spine features (see Materials and Methods). Spines from apical and basal fields were assessed together for these analyses. Spine length and head size are important dimensions in the classification schemes, so we first assessed frequency distributions for these measures. Length was distributed across right-skewed curves for each group (Fig. 3B). There was a significant interaction between group and spine length $(p<0.0001$, two-way ANOVA) with both MA groups having flatter distributions than the young group (kurtosis values: -0.73 , MA-Veh; -1.07 , MA-AK; 0.15, young). Cumulative frequency distributions for spine head diameter revealed similar curves for the MA groups that were right shifted, toward larger head sizes, compared with 2.5 -month-old rats ( $p<0.0001$, twoway RM-ANOVA; Fig. $3 B$ ). Post hoc comparisons indicated that the young rats differed from the MA-Veh rats $(p<0.0001)$, whereas the latter were comparable with the MA-AK rats $(p>0.90)$.

We then assessed the distribution of spines across four standard spine classes referred to as long-thin, mushroom, stubby, and no neck (Harris et al., 1992); spines outside these classes were grouped as other. As shown (Fig. $3 \mathrm{C}$ ), spines in the young group aligned well with the classification scheme with minor variability across individual rats [mean coefficient of variation (CV) across five categories, 15.3\%]. The MA-Veh group was more variable with regard to categories (mean CV, $32.8 \%$ ), whereas the MA-AK group was intermediate $(\mathrm{CV}, 24.8 \%)$. There was a clear interaction between group and spine categories $(p<0.0001$, RMANOVA). Post hoc comparisons indicated that the patterns in the two MA groups were different from that for the young group $(p \leq 0.0002)$ but were not reliably different from each other $(p=$ $0.16)$. With regard to specific types of spines, the 2.5-month-old rats had a higher percentage in the long-thin category than did either MA group $(p<0.01)$, which helps explain the shift in the frequency distribution of head diameters. Collectively, the results indicate that aging causes a measurable increase in the frequency of large spines (length and head size), thereby changing the distribution of spines across conventional categories, and that the AK did not significantly affect these trends.

\section{AK treatments increased the magnitude of LTP}

The functional consequences of treatment were evaluated in electrophysiological studies of hippocampal slices from the AK- and Veh-treated MA rats. Synaptic responses elicited by stimulation of $\mathrm{S}-\mathrm{C}$ projections to the CAlb apical dendritic field (stratum radiatum) were not greatly different between the two groups (Fig. $4 A)$. However, for MA-AK rats decay tau values for S-C fEPSPs were $\sim 14 \%$ greater $(p<0.05$; Fig. $4 B)$ and the input/output curve (number of fibers stimulated/fEPSP slope) was steeper (i.e., $47 \% ; p=0.01$; Fig. $4 C$ ) than for the MA-Veh group. The latter results are as expected from the observed increase in dendritic branches and spines in AK-treated rats: activation of a fixed number of axons will produce a smaller postsynaptic response in a reduced versus more fully elaborated dendritic tree. Paired-pulse facilitation was slightly greater for MA-Veh rats, but this effect did not reach statistical significance ( $p=0.089$, two-way RMANOVA; Fig. $4 D$ ). The facilitation curves are similar to those described for field CA1 in young adult rats (Rex et al., 2005; Trieu et al., 2015).

Percentage LTP was substantially lower $(21.5 \pm 1.8 \%)$ in Vehtreated MA rats compared with the $\sim 50 \%$ values typically reported for young adults (Kramár et al., 2012b). AK treatment increased the magnitude of LTP $(31.3 \pm 2.3 \%, p=0.002$, MA-AK vs MA-Veh; Fig. 4E) as assessed 50-60 min after TBS. Recent work uncovered an "LTP2" effect in slices from young adults, wherein a second application of TBS doubles potentiation if applied at least $50 \mathrm{~min}$ after the first (Kramár et al., 2012b). This effect was present in both MA groups with the increment in potentiation, from LTP1 to LTP2, being greater in AK-treated rats (Veh, $13.3 \pm 3.1$; AK, $20.8 \pm 2.1$ ), although this change did not reach statistical significance $(p=0.06)$. The initial expression of 

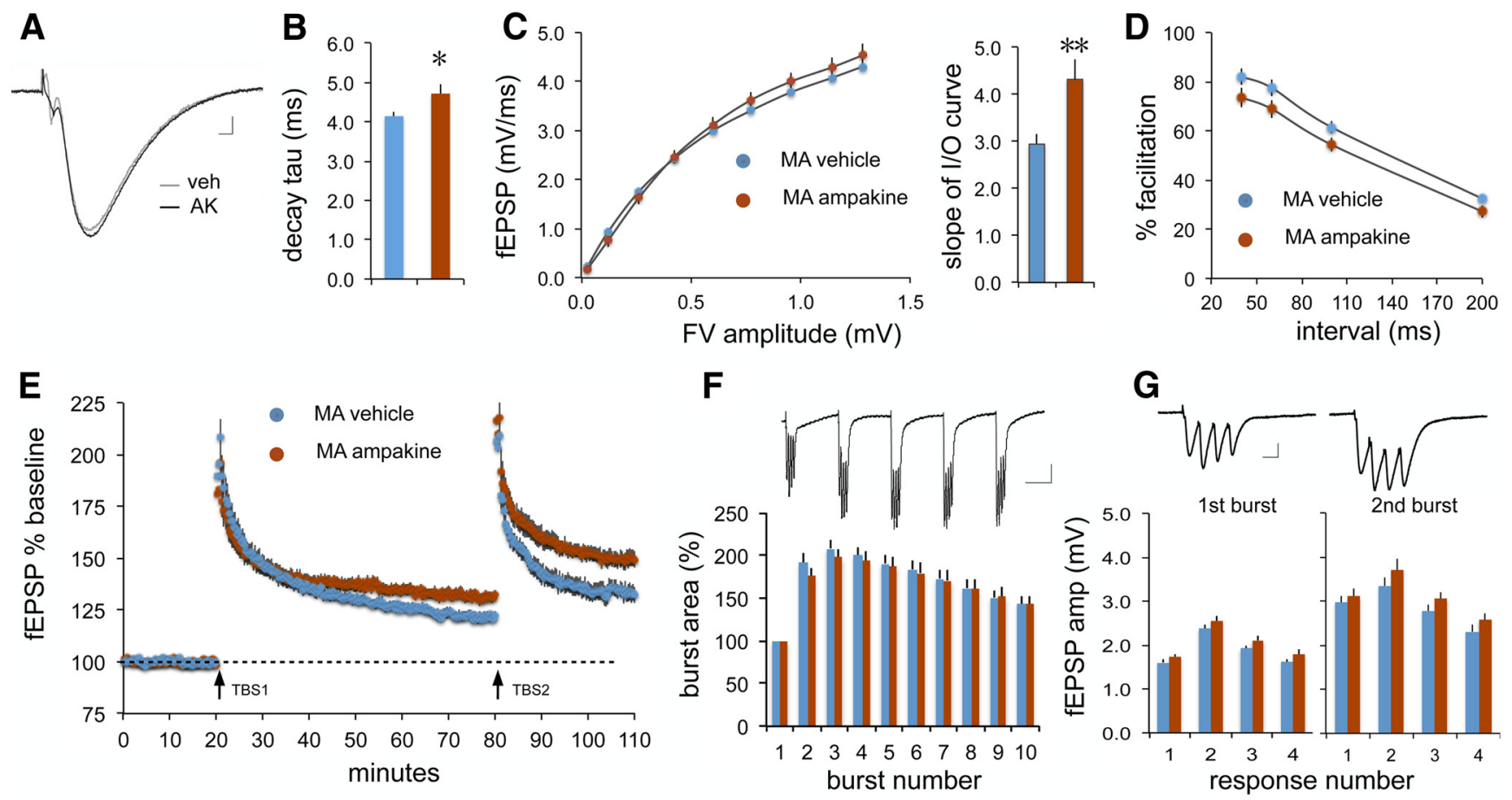

Figure 4. Chronic AK treatment had modest effects on basic synaptic physiology but enhanced LTP. $\boldsymbol{A}, \boldsymbol{B}$, fEPSPs were not different between Veh-treated versus AK-treated MA rats except for an increase in decay tau ( ${ }^{*} p<0.05$, 2-tailed Student's $t$ test). Calibration (in $A$ ): 0.2 mV, 2 ms. C, Input/output curves were steeper for AK- versus Veh-treated MA rats ( ${ }^{* *} p=0.01$, 2-tail Student's $t$ test; FV, fiber volley). D, Paired-pulse facilitation was not influenced by treatment ( $p>0.05$, RM-ANOVA). $\boldsymbol{E}$, TBS-induced LTP stabilized at a higher level in slices from MA-AK versus MA-Veh rats (statistics in Results); after a second round of TBS (TBS2), group differences in LTP were even greater. $\boldsymbol{F}, \mathbf{G}$, Within-train facilitation of theta burst responses ( $\boldsymbol{F}$ ) and within-burst changes in fEPSPs (G) did not differ between MA groups. Calibration: $\boldsymbol{F}, 0.5 \mathrm{mV}, 100 \mathrm{~ms} ; \boldsymbol{G}, 0.5 \mathrm{mV}, 20 \mathrm{~ms}$. Group means \pm SEMs are shown; $n=5$ rats per group and $3-5$ slices per rat (blue, MA-Veh; red, MA-AK).

LTP1 (through 2 min after TBS) was not different between MAVeh and MA-AK rats, nor were responses during TBS. Past studies using slices from young adults found that response size increases markedly from the first through the fifth burst in a TBS train (Kramár et al., 2004); this within-train facilitation was comparable in the two MA groups (Fig. $4 F$ ). Individual responses to pulses within a burst show a characteristic pattern of change in slices from young adults (Kramár et al., 2004); this within-burst profile was also similar in slices from the two MA groups (Fig. $4 G$ ). In all, the positive effect of the AK treatment on LTP does not appear to be attributable to changes in within-train responses to TBS.

The weak LTP in slices from MA-Veh rats given 3 months of EE housing suggested that environmental enrichment had little effect on age-related losses in potentiation. We investigated this idea by evaluating LTP in slices from MA rats $(n=6)$ that were singly housed in standard cages and given Veh on the same schedule as the EE groups. In these rats, LTP1 and LTP2 (17 \pm 2 and $26 \pm 3 \%$ ) were similar to measures from EE-housed MA-Veh rats $(21.5 \pm 1.8$ and $34.7 \pm 4.2 \%)$.

\section{Behavioral consequences of long-term AK treatment}

To test for learning and memory effects accompanying the morphological and physiological changes with AK treatment, we evaluated exploratory behavior in a novel complex environment quite different from the EE housing: a large, multicompartment open field with local and distant object cues, accessible from an attached darkened refuge chamber. This design generated data related to both learning effects in an unsupervised, high-choice paradigm and the possibility that the prolonged drug treatment affected basic psychological variables, such as the preference for enclosed spaces, arousal, or stereotypy. These data are important with regard to the possibility that any group differences in learning are secondary to other adjustments.

Behavioral tests began in week 5 of enrichment. Rats were placed initially into the refuge and allowed to freely explore the arena for $30 \mathrm{~min}$. To preclude direct effects of circulating drug on behavioral measures, on test days the AK or Veh was given after testing was completed. In conventional open-field studies, rapid decreases in exploration over time are usually referred to as "habituation" and considered to reflect short-term memory (Walsh and Cummins, 1976). We found that both AK- and Veh-treated enriched MA rats showed steady decreases in distance traveled in the complex arena over the course of the first session. The total distance traveled in the arena over $30 \mathrm{~min}$ and the rate of decrease over the session measured in six 5 min time intervals were surprisingly similar between the two groups $(62.3 \pm 5.6$ vs $62.2 \pm$ $6.2 \mathrm{~m}$, with slopes $-3.01 \pm 0.26 \mathrm{vs}-3.05 \pm 0.24$ for MA-AK and MA-Veh, respectively). The number of forays from the refuge into the arena also began high and decreased markedly over the first 15 min of session 1 for both groups (Fig. 5A,B).

Rats were returned to the same complex environment 4 d later to test for long-term memory. Exploration of the complex arena as measured by distance traveled dropped $\sim 25 \%$ from session 1 to session 2 ( $p=0.009$ and $p=0.003$ for MA-AK and MA-Veh, respectively, two-tailed within-subject $t$ test), indicating that memory of the arena was retained from session 1 to session 2 by both groups. However, there was also a pronounced drop in the number of forays made during the first 10 min of session 2 in MA-AK rats ( $p=0.0002$, RM-ANOVA for entire session 2$)$ with no decrease between sessions in this measure for MA-Veh rats (Fig. 5A,B). Additional tests conducted 1 and 2 weeks later showed that, for MA-AK rats, foray counts during the first $10 \mathrm{~min}$ of the sessions stabilized near values for session 2, except for an 
A
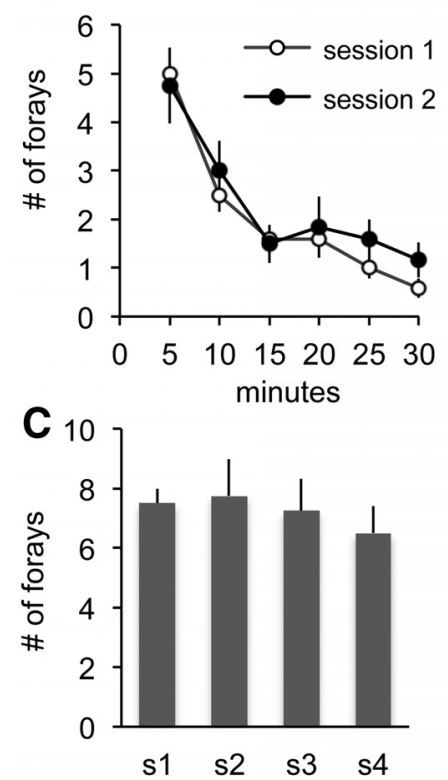

E
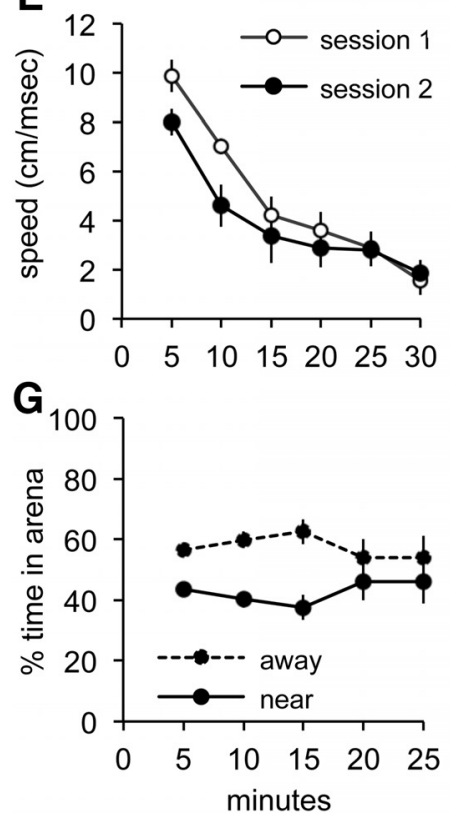

B

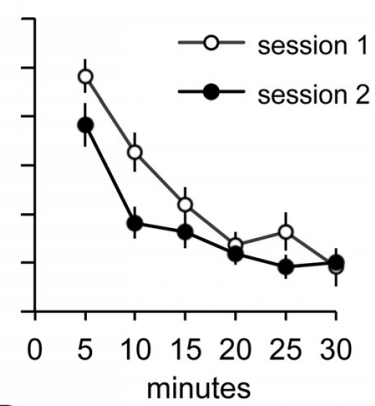

D

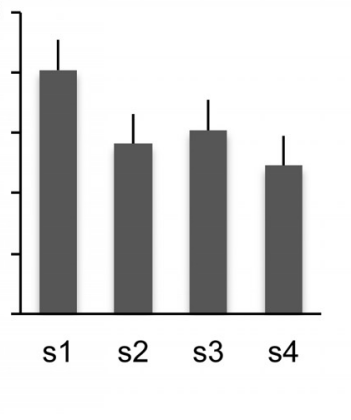

H

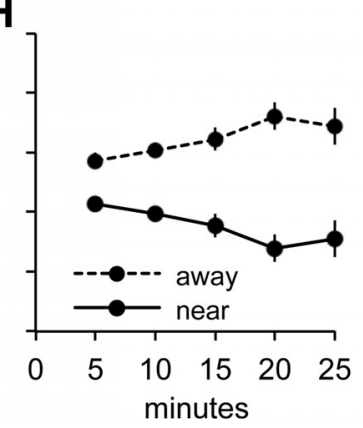

Figure 5. Learning of a novel environment was enhanced by AK treatment. $A, B$, Number of forays from a dark refuge into a novel, complex arena during two sessions, separated by $4 \mathrm{~d}$, by EE-housed, Veh- and AK-treated MA rats; the session ( $s$ ) 1 to $s 2$ difference was significant for AK-treated rats only ( $p=0.0002$, RM-ANOVA; $n=11$ for MA-AK and 12 for MA-Veh groups). $C, D$, Number of forays during the first 10 min in sessions $1-4$ : MA-Veh rat foray counts did not change across test days $(\boldsymbol{C})$, whereas forays decreased from s1 to $s 2$ in the AK group (D) and remained lower through $s 4 . E, F$, Changes in movement speed were similar to those for forays except for changes from $s 1$ to $s 2$ for both MA-Veh and MA-AK rats. $\boldsymbol{G}, \boldsymbol{H}$, Percentage of time in the complex arena spent close to (solid line) versus away from (dotted line) arena walls or barriers during $\mathrm{s} 1$; data for last 5 min of $s 1$ were not plotted because of the paucity of movements for both groups by this time point. Over the course of the session, MA-AK rats $(\boldsymbol{H})$ increased the time spent in open areas, whereas MA-Veh rats $(\boldsymbol{G})$ did not $(p=0.038$, RM-ANOVA).

additional, modest drop from session 3 to session 4 ( $p=0.04$; Fig. $5 C$ ). Notably, the MA-Veh group did not display this form of long-term memory despite the additional experience (Fig. 5D).

As noted, a primary concern in studies using long-term drug treatments involves changes in basic psychological variables, in-

cluding arousal, anxiety, and abnormally repetitive behaviors. Distance traveled during free exploration is a conventional test for arousal (e.g., with stimulants), and the results just described indicate that AK-treated animals did not differ from Veh controls on this measure. Distance is a composite index involving speed (velocity), number, and duration of movements. We evaluated the first of these and found no differences in mean values or rate of habituation on session 1 . As with distance, speed decreased between sessions 1 and 2 for both the MA-AK group $(p<0.006$ for the first $10 \mathrm{~min}$ of sessions 1 vs session 2) and MA-Veh rats $(p<0.009$, RM-ANOVA; Fig. 5E,F). We conclude from these analyses that chronic AK treatment does not influence arousal levels in MA rats.

Anxiety levels in rodents are commonly assessed by measuring preferences for darkened spaces. The apparatus used in the present study included a refuge of this type; both groups spent considerable time in this compartment but to equivalent degrees (Veh, $39.5 \pm 7.6 \%$; AK, $33.4 \pm 7.4 \% ; p=0.57, t$ test). Another common test for rodent anxiety involves the extent to which the animals move away from walls into open spaces (Prut and Belzung, 2003). We measured percentage time spent near walls or barriers during forays into the complex arena versus away from the walls (including the vicinity of objects, the central area, and the region immediately adjacent to the refuge entry) on session 1 and found that both groups spent the same percentage of their arena time adjacent to walls for the first 15 min of session 1 , when anxiety would presumably be maximal (MA-Veh, $42.7 \pm 2.4 \%$; MA-AK, 38.6 $\pm 2.0 \% ; p>0.20)$. However, over the remainder of the session, the AK-treated, but not Veh-treated, animals increased their time spent in the open areas $(p=0.038$, two-way RM-ANOVA; Fig. 5G,H). We suggest that the change in behavior over time in the AK group reflects enhanced learning during session 1, an effect that would help explain the reduction in forays at the beginning of session 2 .

Next, we used a Markov sequence analysis to test whether the rats acquired reliable movement patterns (travel between particular locations) through experience with the complex environment. The technique calculates errors for predictions about an animal's location at different times in the future based on probabilities from its own past behavior for single transitions between sites (van der Heijden et al., 1990; Fig. 6A-C). As expected, prediction errors increased quickly but to the same degree for the two MA groups, as prediction steps were extended ever farther into the future on session 1 (Fig. 6D). For MA-AK rats, the accuracy of predictions began to increase (i.e., the prediction error decreased) on session 2 and then dramatically so on session 3 (Fig. 6D), an effect that did not occur for MA-Veh rats $(p=0.004$ for interaction between prediction step and group on session 3, RM-ANOVA). The difference between MA groups was still present on session 4 ( $p=0.003$; data not shown). These results indicate that the AK-treated rats organized their exploratory behavior into patterns across successive sessions in the test environment and that this effect did not occur in similarly enriched, Vehtreated controls.

Previous work found that aged rats ( $>20$ months) show very different degrees of impairments in spatial memory tasks (Gage et al., 1984; Gallagher et al., 1993; Schulz et al., 2002), resulting in clearly distinct subgroups of animals. We searched for such differential effects of aging in the somewhat younger MA animals used in the present study by using conventional statistical measures for multi-modality (Hartigan and Hartigan, 1985). There was no evidence of subgroups in either the Veh or AK cohorts for short-term memory (habituation on session 1 as assessed by dis- 

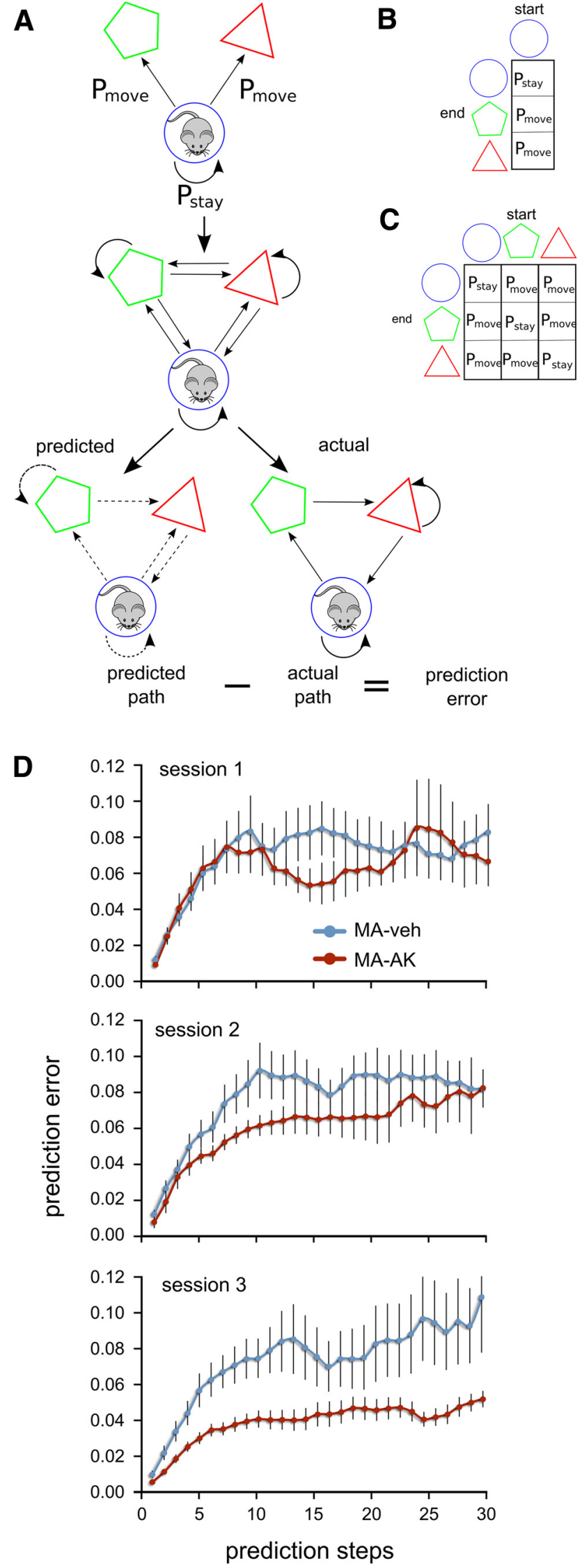

Figure 6. Markov sequence analyses demonstrate that MA rat behavior becomes more predictable with AK treatment. $A$, Flowchart shows how the prediction error was calculated from the predicted and actual paths taken by a rat (using a three-location example; our analyses tance traveled; $p>0.5$ and $p>0.4$ for AK and Veh groups, respectively), long-term memory (decrease in forays between sessions 1 and $2 ; p>0.5$ for both groups), or Markov sequence analyses for session 3 ( $p>0.5$ for both groups). These findings suggest either that living in the EE offsets the differential influence of aging on individuals or that this effect does not emerge by 13 months of age.

\section{Treatment effects on body weight and locomotor activity}

General measures of animal health were assessed for all EEhoused MA rats receiving AK or Veh. Body weight changes during the 3 month period were small and comparable for Veh (start, $590.0 \pm 15.6 \mathrm{~g}$; end, $624.5 \pm 23.5 \mathrm{~g}$ ) and AK (start, $596.1 \pm 14.5 \mathrm{~g}$; end, $649.9 \pm 17.8 \mathrm{~g}$ ) groups. Weekly food intake was also similar $(175 \pm 5 \mathrm{~g}$ for MA-Veh vs $173 \pm 6 \mathrm{~g}$ for MA-AK). By these conventional measures, the treatments did not produce negative side effects.

EE housing included access to a running wheel. Weekly running distance for three rats (two MA-Veh; one MA-AK) was far greater ( $>15$ SDs) than for means of the others. A comparison of values for the more typical $(88 \%)$ rats indicated that distance run was lower for MA-AK rats than for MA-Veh rats (Fig. $7 A ; p=$ 0.038 , RM-ANOVA). Within-group variance was high for MAVeh rats and so we log-transformed the data, which normalized the quantile-quantile ( $Q-Q)$ plot (Fig. 7B). The difference between the MA groups was significant under these conditions ( $p=0.023$, RM-ANOVA), with the MA-AK group running less. Importantly, the same rats were not hypoactive during tests of exploration as described above. Given that CX929 has a short half-life (Rex et al., 2006), these observations provide evidence that the AK caused lasting changes that depressed the tendency of rats to engage in intense, repetitive activity.

This amount of running is considerably lower than that described for young animals placed in a conventional running wheel apparatus and accords with previous work showing that older animals tend to run less with evident declines beginning at 2-6 months of age (for review, see Sherwin, 1998). Moreover, wheel running is less intense in complex environments (Roper and Polioudakis 1977; Sherwin, 1998).

\section{Discussion}

A substantial body of evidence indicates that brain aging begins surprisingly early during adult life and then progresses steadily, resulting in significant declines for a number of behavioral and physiological variables by middle age. Dendritic retraction, which is described for MA animals, is a plausible contributor to these functional losses. Results described here suggest that pharmacologically stimulated dendritic elaboration and spine formation are feasible in MA animals and are accompanied by

$\leftarrow$

included 10 zones). At top, the available options at a given position are shown (Pmove left Pmove right, or Pstay), with the probability of moving to a new location or staying indicated by $P$. Matrix for quantifying these probabilities is shown in $\boldsymbol{B}$. At the next stage of the flow chart in $\boldsymbol{A}$, all possible options for all possible positions are shown. This was translated, over the course of the entire 10 min quantified, into the matrix shown in $C$. The latter was then used to generate a predicted path probability for longer time bins as illustrated at the bottom, left of $\boldsymbol{A}$. The predicted path probability was then tested against the actual path the animal took along that time bin to produce the prediction error. $\boldsymbol{D}$, Prediction errors for a Markov sequence analysis as a function of the number of prediction steps ( $1 \mathrm{step}=2.5 \mathrm{~s}$ ) into the future for sessions 1,2 , and 3. As shown, in AK-treated MA rats, there was a significant reduction of prediction errors, an effect that was not evident in MA-Veh rats ( $p=0.004$ for interaction between step and group, RM-ANOVA). Groups included nine MA-AK and 11 MA-Veh rats. 


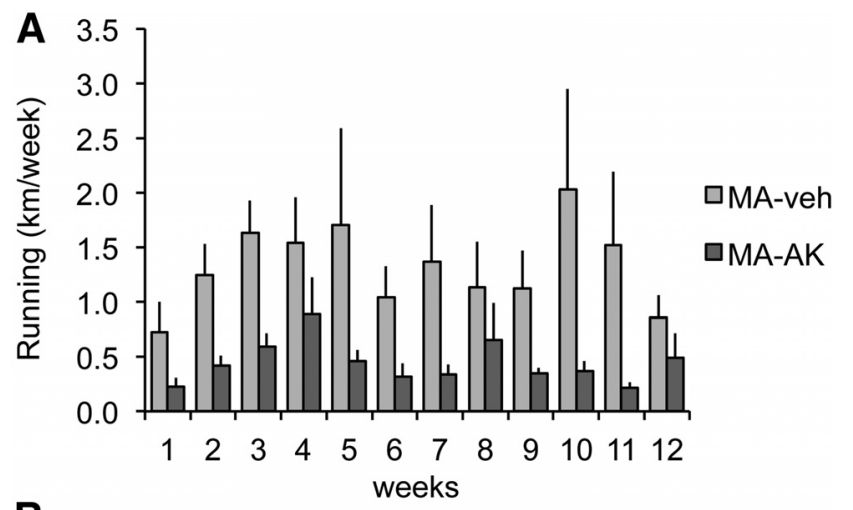

B

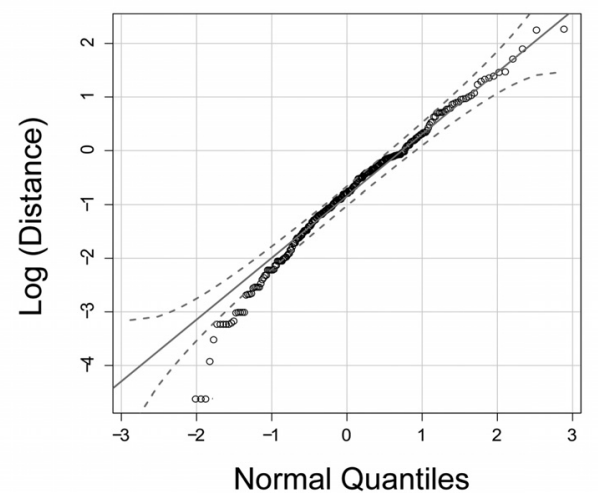

Figure 7. AK treatment reduced voluntary wheel running in MA rats. $A$, Mean \pm SEM distance run per week during the EE/treatment period. MA-AK rats $(n=11)$ ran less than MA-Veh rats $(n=10 ; p=0.03$, RM-ANOVA). $\boldsymbol{B}$, The $\mathbf{Q}-\mathbf{Q}$ plot shows the log-transformed wheel running data from the MA-Veh and MA-AK groups. The log-transformed data were much closer to the quantiles expected for a normal fit.

significant improvements to plasticity and learning. We found that treatment with the AK CX929 reversed the dendritic retraction otherwise evident in MA rats. Importantly, these experiments were conducted on EE-housed animals; thus, the growth effects were not attributable to an offsetting of losses produced by living in impoverished circumstances. That the compound was given orally and daily over an extended period without unwanted side effects is encouraging with regard to the possibility of a clinically realistic treatment regimen.

Whether the increase in dendritic branching reflects a recovery of processes lost because of aging or instead is attributable to a generalized growth effect is a difficult question, and our results do not discriminate between these possibilities. The present work also does not speak to when age-associated changes in dendritic morphology emerge between 2.5 and 13 months of age for environmentally enriched rats. The similarity of the Sholl curves for the young and MA-AK rats, one of the more surprising results from the project, suggests that growth was constrained by factors that limit the dendritic arbor in young animals living in complex environments. At the same time, spine density was elevated in AK-treated MA rats compared with both young and MA-Veh rats. This appears to constitute a case of heightened spine formation as opposed to restoration of values found under what might be considered to be normal conditions (i.e., in EE-housed 2.5month-old rats). Considered together with the increase in dendritic branching and length, the spine density results, obtained from counts of limited dendritic spans, likely underestimate the actual increase in numbers of spines produced by the AK treatment. Pertinent to this, recent work showed that months-long treatment with
Riluzole, a compound that enhances glial uptake of glutamate and promotes excitatory transmission, increases clustering of thin dendritic spines and learning scores in MA rats (Pereira et al., 2014); whether the compound also offsets age-associated losses in dendritic branches is an important question for future work.

Physiological changes associated with CX929 treatment in the present studies are consistent with the increase in dendrites and spines. Expansion of the postsynaptic surface, and spine density in particular, should promote LTP because depolarizing interactions between neighboring active spines will be increased (Winnubst and Lohmann, 2012). In accord with this, the magnitude of LTP was clearly greater in slices from drug- vs Veh-treated MA rats. Despite this, treatments did not influence within-train facilitation of theta burst responses or the fEPSP amplitude shifts within single burst responses. Theta response dynamics are shaped by a complex array of variables (Kramár et al., 2004), and the possibility that moderate changes in the NMDA receptor component were obscured by other factors is a vital question for future work. All of the young animals in the present study were used to build a baseline group against which to compare dendritic measures in the MA groups, and so LTP was not tested. However, past work described a significant effect of aging on LTP (Landfield and Lynch, 1977; Rex et al., 2005, 2006; Burke and Barnes, 2006; Lynch et al., 2006; Kumar, 2011); it is noteworthy that environmental enrichment by itself did not offset the dendritic losses or LTP impairment that accompany aging.

The above results indicate that chronic AK treatment did not disturb basic synaptic physiology but had positive effects on LTP, a form of plasticity thought to underlie learning (Bliss and Collingridge, 1993). There was also no evidence for disturbances to basic features of behavior (speed of movements, time in compartments, etc.) in a novel complex environment, but learning was improved. The decrease in wheel running by MA-AK rats in their EE housing is notable; however, given that food intake and weight changes were not affected and the apparent normalcy of movements in novel circumstances, this difference was not likely attributable to illness or lethargy. An alternative possibility is that AK treatment influences functions in key forebrain areas (orbitofrontal cortex and hippocampus) known to suppress wheel running (Lynch, 1970; Rhodes et al., 2005). Dendritic retraction has been observed with aging in the frontal cortex (rats, nonhuman primates, and humans; Dickstein et al., 2013; Samson and Barnes, 2013); the presence of such an effect in MA rats, and its diminution by AK treatment, could account for the observed effects on running.

The paradigm used for behavioral studies involved a considerable amount of exploration in an extended, complex arena with multiple compartments and so numerous decision points. These features allowed for testing of group differences in psychological states (anxiety and arousal), a critical point with regard to the behavioral profile associated with the neurobiological changes produced by the experimental treatment and to its plausibility as a therapeutic strategy. Two widely used measures of arousal (initial amount of exploration and speed of movement) were not detectably different between the Veh and AK groups. Anxiety, as assessed by preference for darkened areas or a tendency to avoid open areas, was also comparable in Veh and AK groups. The Markov sequence analysis did not detect any evidence for a higher degree of repetition in drug- versus Veh-treated rats on session 1 . We conclude from these findings that chronic administration of the $\mathrm{AK}$ and the neurobiological effects resulting from it do not produce significant psychological or motor disturbances. However, as noted, the tests were conducted after a considerable delay from drug administration; the possibility that the 
compound produces short-term effects on the above variables, during the course of long-term chronic administration, is an important issue for translation and remains to be tested.

Although AK treatment did not detectably alter basic exploratory movements and both MA groups evidenced short- and long-term learning and memory of the complex arena, the drug treatment did result in a form of long-term memory that was absent in the Veh cases, even after multiple trials. Specifically, AK-treated but not Veh-treated MA rats showed a marked drop in counts of forays from a darkened chamber into the larger multicompartment arena between test sessions 1 and 2. Probably related to this, rats in the drug but not Veh group detectably broadened their exploration pattern during the later phases of session 1 . We suggest that the drop in foray counts in session 2 can be regarded as evidence of enhanced learning on session 1 , allowing for animals to quickly recognize the test situation in session 2 ("situational awareness") and so reduce the number of exploratory episodes. Veh-treated animals apparently failed to acquire this type of memory even after repeated testing sessions.

A Markov sequence analysis detected evidence for a second type of learning in the rats given chronic AK administration but not in Veh-treated animals: the predictability of movements between locations increased markedly across successive sessions. This suggests that brain changes produced by the drug enabled the connection of individual search movements into long, reusable sequences. Recent work supports a critical role for the hippocampus in encoding of serial information into episodic memory by rodents and humans (Yassa and Stark, 2011; for review, see Reagh and Yassa, 2014). Self-organization of sequential behaviors in the face of considerable complexity could be related to this type of hippocampal operation. If so, then the restoration of dendritic branches along with the enhanced plasticity would be logically related to the predictability results described here.

It will be important in future work to determine the minimum period over which dendritic growth can be produced and its correlation over time with the behavioral and electrophysiological changes reported here. Insights into mode of action would be of great significance with regard to the poorly understood, fundamental question of why pro-growth processes fail during the course of mammalian aging. Pertinent to this, we showed previously that chronic AK treatment in the R6/2 mouse model of Huntington's disease, a condition associated with striatal neurodegeneration, markedly reduced the progression of striatal shrinkage, neuronal deterioration, and motor impairments with age (Simmons et al., 2011). Accompanying these effects were marked increases in the growth-promoting factor BDNF in the AK-treated animals (Simmons et al., 2011); this is consistent with other studies showing that positive AMPA receptor modulators increase BDNF expression, including in MA animals (Lauterborn et al., 2003; Rex et al., 2006; Simmons et al., 2009; Kramár et al., 2012a). Subsequent work with a small-molecule ligand that is specific for TrkB also showed reductions in motor impairments and neuropathology in R6/2 mice (Simmons et al., 2013), further supporting a drug-based strategy for enhancing BDNF-TrkB signaling to offset age-related pathology. The feasibility of this approach will depend on how candidate compounds trigger morphological changes and improve outcomes and the degree to which they can be administered over extended periods without unwanted side effects. As described, the results reported here are encouraging with regard to the latter point.

In summary, the present findings constitute evidence that positive modulation of fast excitatory transmission over extended periods triggers dendritic and spine growth in the MA brain. The effects were not accompanied by evident disruptions of brain function but instead were associated with enhanced plasticity and encoding of what appear be complex forms of memory. Thus, the findings describe a novel and relatively simple approach to treating age-related deterioration of brain.

\section{References}

Arai AC, Kessler M, Rogers G, Lynch G (2000) Effects of the potent ampakine CX614 on hippocampal and recombinant AMPA receptors: interactions with cyclothiazide and GYKI 52466. Mol Pharmacol 58:802-813. CrossRef Medline

Arai AC, Xia YF, Rogers G, Lynch G, Kessler M (2002) Benzamide-type AMPA receptor modulators form two subfamilies with distinct modes of action. J Pharmacol Exp Ther 303:1075-1085. CrossRef Medline

Baudry M, Kramar E, Xu X, Zadran H, Moreno S, Lynch G, Gall C, Bi X (2012) Ampakines promote spine actin polymerization, long-term potentiation, and learning in a mouse model of Angelman syndrome. Neurobiol Dis 47:210-215. CrossRef Medline

Bliss TV, Collingridge GL (1993) A synaptic model of memory: long-term potentiation in the hippocampus. Nature 361:31-39. CrossRef Medline

Burke SN, Barnes CA (2006) Neural plasticity in the ageing brain. Nat Rev Neurosci 7:30-40. CrossRef Medline

Dickstein DL, Weaver CM, Luebke JI, Hof PR (2013) Dendritic spine changes associated with normal aging. Neuroscience 251:21-32. CrossRef Medline

Dickstein DL, Kabaso D, Rocher AB, Luebke JI, Wearne SL, Hof PR (2007) Changes in the structural complexity of the aged brain. Aging Cell 6:275284. CrossRef Medline

Gage FH, Dunnett SB, Björklund A (1984) Spatial learning and motor deficits in aged rats. Neurobiol Aging 5:43-48. CrossRef Medline

Gallagher M, Burwell R, Burchinal M (1993) Severity of spatial learning impairment in aging: development of a learning index for performance in the Morris water maze. Behav Neurosci 107:618-626. CrossRef Medline

Hao J, Rapp PR, Leffler AE, Leffler SR, Janssen WG, Lou W, McKay H, Roberts JA, Wearne SL, Hof PR, Morrison JH (2006) Estrogen alters spine number and morphology in prefrontal cortex of aged female rhesus monkeys. J Neurosci 26:2571-2578. CrossRef Medline

Harris KM, Jensen FE, Tsao B (1992) Three-dimensional structure of dendritic spines and synapses in rat hippocampus (CA1) at postnatal day 15 and adult ages: implications for the maturation of synaptic physiology and long-term potentiation. J Neurosci 12:2685-2705. Medline

Hartigan JA, Hartigan PM (1985) The dip test of unimodality. Ann Stat 13:70-84. CrossRef

Jin R, Clark S, Weeks AM, Dudman JT, Gouaux E, Partin KM (2005) Mechanism of positive allosteric modulators acting on AMPA receptors. J Neurosci 25:9027-9036. CrossRef Medline

Kramár EA, Lin B, Lin CY, Arai AC, Gall CM, Lynch G (2004) A novel mechanism for the facilitation of theta-induced long-term potentiation by brain-derived neurotrophic factor. J Neurosci 24:5151-5161. CrossRef Medline

Kramár EA, Chen LY, Lauterborn JC, Simmons DA, Gall CM, Lynch G (2012a) BDNF infusion and upregulation rescues synaptic plasticity in middle-aged ovariectomized rats. Neurobiol Aging 33:708-719. CrossRef Medline

Kramár EA, Babayan AH, Gavin CF, Cox CD, Jafari M, Gall CM, Rumbaugh G, Lynch G (2012b) Synaptic evidence for the efficacy of spaced learning. Proc Natl Acad Sci U S A 109:5121-5126. CrossRef Medline

Kumar A (2011) Long-term potentiation at CA3-CA1 hippocampal synapses with special emphasis on aging, disease, and stress. Front Aging Neurosci 3:7. Medline

Landfield PW, Lynch G (1977) Impaired monosynaptic potentiation in in vitro hippocampal slices from aged, memory-deficient rats. J Gerontol 32:523-533. CrossRef Medline

Lauterborn JC, Lynch G, Vanderklish P, Arai A, Gall CM (2000) Positive modulation of AMPA receptors increases neurotrophin expression by hippocampal and cortical neurons. J Neurosci 20:8-21. Medline

Lauterborn JC, Jafari M, Babayan AH, Gall CM (2015) Environmental enrichment reveals effects of genotype hippocampal spine morphologies in the mouse model of fragile X syndrome. Cereb Cortex 25:516-527. CrossRef Medline

Lauterborn JC, Troung GS, Baudry M, Bi X, Lynch G, Gall CM (2003) 
Chronic elevation of brain-derived neurotrophic factor by ampakines. J Pharmacol Exp Ther 307:297-305. CrossRef Medline

Lynch GS (1970) Separable forebrain systems controlling different manifestations of spontaneous activity. J Comp Physiol Psychol 70:48-59. CrossRef Medline

Lynch G (2006) Glutamate-based therapeutic approaches: ampakines. Curr Opin Pharmacol 6:82-88. CrossRef Medline

Lynch G, Rex CS, Gall CM (2006) Synaptic plasticity in early aging. Ageing Res Rev 5:255-280. CrossRef Medline

Markham JA, McKian KP, Stroup TS, Juraska JM (2005) Sexually dimorphic aging of dendritic morphology in CA1 of hippocampus. Hippocampus 15:97-103. CrossRef Medline

Miguéns M, Kastanauskaite A, Coria SM, Selvas A, Ballesteros-Yañez I, DeFelipe J, Ambrosio E (2015) The effects of cocaine self-administration on dendritic spine density in the rat hippocampus are dependent on genetic background. Cereb Cortex 25:56-65. CrossRef Medline

Navarro-Mora G, Fabene PF, van Luijtelaar G (2011) Early onset of agerelated changes on neural processing in rats. Physiol Behav 103:134-143. CrossRef Medline

Nell HJ, Whitehead SN, Cechetto DF (2015) Age-dependent effect of $\beta$-amyloid toxicity on basal forebrain cholinergic neurons and inflammation in the rat brain. Brain Pathol 25:531-542. CrossRef Medline

Nimchinsky EA, Sabatini BL, Svoboda K (2002) Structure and function of dendritic spines. Annu Rev Physiol 64:313-353. CrossRef Medline

Ohm TG, Diekmann S (1994) The use of Lucifer Yellow and Mini-Ruby for intracellular staining in fixed brain tissue: methodological considerations evaluated in rat and human autopsy brains. J Neurosci Methods 55:105110. CrossRef Medline

Pereira AC, Lambert HK, Grossman YS, Dumitriu D, Waldman R, Jannetty SK, Calakos K, Janssen WG, McEwen BS, Morrison JH (2014) Glutamatergic regulation prevents hippocampal-dependent age-related cognitive decline through dendritic spine clustering. Proc Natl Acad Sci U S A 111: 18733-18738. CrossRef Medline

Petralia RS, Mattson MP, Yao PJ (2014) Communication breakdown: the impact of ageing on synapse structure. Ageing Res Rev 14:31-42. CrossRef Medline

Prut L, Belzung C (2003) The open field as a paradigm to measure the effects of drugs on anxiety-like behaviors: a review. Eur J Pharmacol 463:3-33. CrossRef Medline

Reagh ZM, Yassa MA (2014) Object and spatial mnemonic interference differentially engage lateral and medial entorhinal cortex in humans. Proc Natl Acad Sci U S A 111:E4264-E4273. CrossRef Medline

Rex CS, Kramár EA, Colgin LL, Lin B, Gall CM, Lynch G (2005) Long-term potentiation is impaired in middle-aged rats: regional specificity and reversal by adenosine receptor antagonists. J Neurosci 25:5956-5966. CrossRef Medline

Rex CS, Lauterborn JC, Lin CY, Kramár EA, Rogers GA, Gall CM, Lynch G (2006) Restoration of long-term potentiation in middle-aged hippocampus after induction of brain-derived neurotrophic factor. J Neurophysiol 96:677-685. CrossRef Medline

Rhodes JS, Gammie SC, Garland T Jr (2005) Neurobiology of mice selected for high voluntary wheel-running activity. Integr Comp Biol 45:438-455. CrossRef Medline
Robitsek RJ, Fortin NJ, Koh MT, Gallagher M, Eichenbaum H (2008) Cognitive aging: a common decline of episodic recollection and spatial memory in rats. J Neurosci 28:8945-8954. CrossRef Medline

Roper TJ, Polioudakis E (1977) The behaviour of Mongolian gerbils in a semi-natural environment, with special reference to ventral marking, dominance and sociability. Behaviour 61:207-237. CrossRef

Samson RD, Barnes CA (2013) Impact of aging brain circuits on cognition. Eur J Neurosci 37:1903-1915. CrossRef Medline

Schulz D, Huston JP, Jezek K, Haas HL, Roth-Härer A, Selbach O, Luhmann HJ (2002) Water maze performance, exploratory activity, inhibitory avoidance and hippocampal plasticity in aged superior and inferior learners. Eur J Neurosci 16:2175-2185. CrossRef Medline

Sherwin CM (1998) Voluntary wheel running: a review and novel interpretation. Anim Behav 56:11-27. CrossRef Medline

Simmons DA, Rex CS, Palmer L, Pandyarajan V, Fedulov V, Gall CM, Lynch G (2009) Up-regulating BDNF with an ampakine rescues synaptic plasticity and memory in Huntington's disease knockin mice. Proc Natl Acad Sci U S A 106:4906-4911. CrossRef Medline

Simmons DA, Mehta RA, Lauterborn JC, Gall CM, Lynch G (2011) Brief ampakine treatments slow the progression of Huntington's disease phenotypes in R6/2 mice. Neurobiol Dis 41:436-444. CrossRef Medline

Simmons DA, Belichenko NP, Yang T, Condon C, Monbureau M, Shamloo M, Jing D, Massa SM, Longo FM (2013) A small molecule TrkB ligand reduces motor impairment and neuropathology in R6/2 and BACHD mouse models of Huntington's disease. J Neurosci 33:18712-18727. CrossRef Medline

Stäubli U, Perez Y, Xu FB, Rogers G, Ingvar M, Stone-Elander S, Lynch G (1994) Centrally active modulators of glutamate (AMPA) receptors facilitate the induction of LTP in vivo. Proc Natl Acad Sci U S A 91:11158 11162. CrossRef Medline

Swanger SA, Yao X, Gross C, Bassell GJ (2011) Automated 4D analysis of dendritic spine morphology: applications to stimulus-induced spine remodeling and pharmacological rescue in a disease model. Mol Brain 4:38. CrossRef Medline

Trieu BH, Kramár EA, Cox CD, Jia Y, Wang W, Gall CM, Lynch G (2015) Pronounced differences in signal processing and synaptic plasticity between piriform-hippocampal network stages: a prominent role for adenosine. J Physiol 593:2889-2907. CrossRef Medline

van der Heijden PG, de Vries H, van Hooff JA (1990) Correspondence analysis of transition matrices, with special attention to missing entries and asymmetry. Anim Behav 40:49-64. CrossRef

Walsh RN, Cummins RA (1976) The Open-Field Test: a critical review. Psychol Bull 83:482-504. CrossRef Medline

Wilson IA, Gallagher M, Eichenbaum H, Tanila H (2006) Neurocognitive aging: prior memories hinder new hippocampal encoding. Trends Neurosci 29:662-670. CrossRef Medline

Winnubst J, Lohmann C (2012) Synaptic clustering during development and learning: the why, when, and how. Front Mol Neurosci 5:70. CrossRef Medline

Yassa MA, Stark CE (2011) Pattern separation in the hippocampus. Trends Neurosci 34:515-525. CrossRef Medline 